\title{
The Behavior of Bacteria Designed for Biodegradation
}

\author{
Juan L. Ramos'", Eduardo Díaz², David Dowling3, Victor de Lorenzo4, Soren Molin', Fergal O'Gara3, Cayo Ramos' and \\ Kenneth N. Timmis ${ }^{2}$
}

${ }^{1}$ Consejo Superior de Investigaciones Científicas-Estación Experimental del Zaidín, Department of Biochemistry and Molecular and Cellular Biology of Plants, Granada, Spain. ${ }^{2}$ Gesellschaft für Biotechnologische Forschung, Division of Microbiology, Braunschweig, Germany. ${ }^{3}$ University College Cork, Department of Microbiology, Cork, Ireland. ${ }^{4}$ Consejo Superior de Investigaciones Científicas-Centro de Investigaciones Biologicas, Department of Microbiology, Madrid, Spain. ${ }^{5}$ Technical University of Denmark, Department of Microbiology, Lyngby, Denmark. *Corresponding author (e-mail: jlramos@samba.cnb.uam.es).

Mineralization of organic molecules by microbes is essential for the carbon cycle to operate. The massive mobilization of compounds stored in natural resources, or the introduction of xenobiotics into the biosphere, leads to unidirectional fluxes, which result in the persistance of a number of chemicals in the biosphere, and thus constitute a source of pollution. Molecular biology offers the tools to optimize the biodegradative capacities of microorganisms, accelerate the evolution of "new" activities, and construct totally "new" pathways through the assemblage of catabolic segments from different microbes. Although the number of genetically engineered microbes (GEMs) for potential use in biodegradation is not large, these recombinant microbes function in microcosms according to their design. The survival and fate of recombinant microbes in different ecological niches under laboratory conditions is similar to what has been observed for the unmodified parental strains. rDNA, both on plasmids and on the host chromosome, is usually stably inherited by GEMs. The potential lateral transfer of rDNA from the GEMs to other microbes is significantly diminished, though not totally inhibited, when rDNA is incorporated on the host chromosome. The behavior and fate of GEMs can be predicted more accurately through the coupling of regulatory circuits that control the expression of catabolic pathways to killing genes, so that the GEMs survive in polluted environments, but die when the target chemical is eliminated.

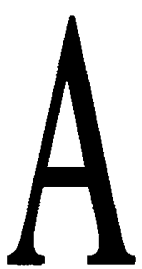

large proportion of organic compounds of biological and chemical origin are ultimately mineralized (ie degraded to carbon dioxide, water and other inorganic compounds), predominantly by microorganisms, as part of the continuous cycling of carbon between inorganic and organic states. Mineralization of a compound involves its structural alteration and the formation of metabolic intermediates that serve either as carbon skeletons for cellular constituents or as fuels for energy generation (Fig. 1).

However, not all organic molecules are readily mineralized, and these may persist in the biosphere. When the structural elements of such compounds are chemically very stable, have novel features not generally found in organic molecules of biological origin, are toxic for microorganisms, or inhibit degradative enzymatic attack, then the compound itself is said to be recalcitrant to biological degradation (Fig. 1).

Mineralization of organic compounds is a central feature of the carbon cycle and is a process critical to the maintenance of life on this planet. However, biotransformation or partial degradation of an organic compound does not necessarily have a beneficial outcome: microbes may not gain energy for growth, even more recalcitrant compounds or highly reactive products which undergo thereafter chemical changes such as polymerization may be formed (Fig. 1). The resulting products may be even more toxic than their precursors.

Most naturally occurring molecules are easily mineralized, as are industrial chemicals with structure similar to organic compounds of biological origin. However, many xenobiotics (compounds that exhibit structural elements not found in natural ones) may be recalcitrant, or may be transformed to recalcitrant products. Industrial chemicals have been present in the environment for only an instant in evolutionary time, a period that in some cases has not been long enough for the appropriate functional groups to evolve in catalytic sites of enzymes. In other cases accumulation of chemicals in the biosphere is the result of the mobilization of large amounts of compounds as a consequence of industrial activities. The introduction of xenobiotics or the massive mobilization of compounds present in natural resources cause a problem regarding the integration of these compounds into the natural nutrient cycles. As a consequence of the progressive accumulation of pollutants in the biosphere, environments hostile to biological systems, ie those polluted by aliphatic and aromatic hydrocarbons, chlorinated compounds, nitrotoluenes, dyes, explosives, organic solvents, etc are increasing 1 .

Effective steps should be taken to protect the environment from pollution. With regard to chemical pollutants, it is evident that the manufacture of toxic and recalcitrant compounds should diminish and eventually cease. Such chemicals must be replaced with nontoxic alternatives that can be mineralized. However, these changes will inevitably take a number of years, as the possible negative effects of many compounds have not yet been investigated. This makes active measures necessary to eliminate or detoxify pollutants. One of the most promising approaches is to optimize the biodegradative capacities of microorganisms, accelerate the evolution of new activities, and exploit them to eliminate these pollutants ${ }^{2}$.

The introduction of some chemicals into the environment selects for the evolution of the corresponding catabolic activities, ie, the herbicide 2,4-dichlorophenoxyacetic acid (2,4-D) and insecticides such as DDT and parathion, can be mineralized by single microbes or communities of microbes ${ }^{3-5}$. However, other chemicals are highly recalcitrant, ie, organic solvents, polychlorinated aromatics, dioxins, dibenzofurans, etc. In such cases the evolution of new activities in the laboratory may be helpful because the frequency and types of genetic events needed (e.g., mutation, alteration of gene expression, gene dosage, gene transfer, etc.) can be carefully controlled under selective conditions ${ }^{2,6}$. The experimental evolution of catabolic 


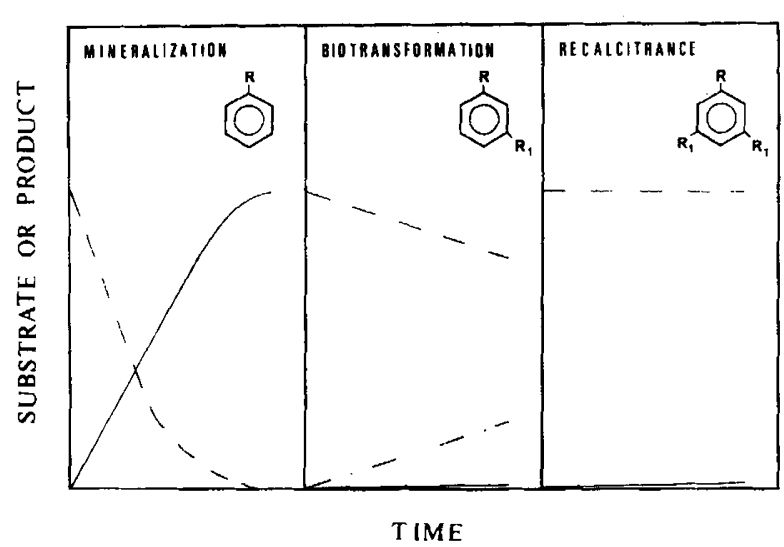

FIGURE 1. Schematic representation of the relationships between microblal growth, fate of substrates and accumulation of intermediates after exposure of a microorganism or microbial community to an organic chemical. If the microorganism (or microbial community) possesses a catabolic pathway for the complete mineralization of the compound, the amount of compound will decrease steadily (-_-) while biomass increases $(\longrightarrow$ ) (left panel). If the compound is co-metabolized, ie, partially degraded to another compound in the absence of energetic gain to the organism that performs the transformation, there may be partial or complete loss of the compound (--) with the accumulation of a corresponding amount of an intermediate (-..-). No increase in cell mass occurs as a result of this transformation (central panel). When recalcitrant substrates are not metabolized to any significant extent, intermediates do not accumulate, and no microbial growth is observed (right panel).<smiles>CCc1ccc(C(=O)O)cc1</smiles><smiles>C[12CH3]</smiles><smiles>CC(C)(C)C</smiles><smiles>Cc1ccc(O)c(O)c1</smiles><smiles>C[Te]</smiles>
$\mathrm{CO}_{2}+\mathrm{H}_{2} \mathrm{O}$<smiles>Cc1ccc(C(=O)O)cc1</smiles><smiles>CCc1ccc(C(=O)O)cc1</smiles><smiles>CCc1ccc(C(=O)O)cc1</smiles><smiles>CCc1ccc(O)c(O)c1</smiles><smiles>CC(C)(C)C(C)(C)C</smiles><smiles>CCc1ccc(O)c(O)c1</smiles>

$\checkmark x Y L E 106$

$\mathrm{CO}_{2}+\mathrm{H}_{2} \mathrm{O}$
FIGURE 2. Horizontal expansion of the TOL meta-cleavage pathway for metabolism of alkylbenzoates. Sequencial recruitment of mutations to overcome bottleneck steps in the mineralization of p-ethylbenzoate by the meta-cleavage pathway of the TOL plasmid of Pseudomonas putida.

pathways offers considerable potential for accelerating the evolution of bacteria able to degrade toxic industrial chemicals, and this may be useful for reducing environmental pollution. Several strategies have been successfully applied to construct bacteria able to eliminate a wide range of organic solvents, such as toluene derivatives, a number of chlorinated aromatics arising from human industrial activities, for example chlorobenzoates and chlorophenols, and the more recalcitrant polychlorinated biphenyls and explosives such as 2,4,6-trinitrotoluene $\mathrm{e}^{7-14}$.

Furthermore, some of these recombinant bacteria and their parental wild-type strains have been selectively introduced in polluted and nonpolluted environments, and their survival, performance and ability to transfer recombinant DNA (rDNA) have been monitored. Active conditional biological containment systems based on several killing functions and coupled to the regulatory elements of catabolic pathways have been developed and tested in model recombinant bacteria in which survival or death was preprogrammed. In addition, to decrease the transfer and spread of new traits from the released GEMs to the indigenous microbiota, the GEMs can be supplied with a universal barrier to gene dispersal, based on killing function conferred by the colicin E3 RNase. These issues are reviewed below.

\section{Recombinant Bacteria}

Bacteria belonging to the genus $P$ seudomonas exhibit a wide range of metabolic activities against natural and xenobiotic compounds. The so-called fluorescent Pseudomonas group includes strains whose biochemical, physiological and genetic characteristics have been well characterized ${ }^{15,16}$. A number of genetic tools-wide host range vectors, transposons and mini-transposons, reverse genetics etc...-have made it possible to design recombinant derivatives of this group of bacteria with increased biodegradative properties ${ }^{6,17}$. Several strains with natural biodegradative properties have been intensively investigated to expand the range of xenobiotics they can degrade. Some of these constructions are summarized below.

1. Pseudomonas putida KT2440 harboring the self-transmissible TOL plasmid pWWO grows on a variety of aromatic hydrocarbons used as solvents, including toluene, $m$ - and $p$ xylene, and $m$-ethyltoluene ${ }^{18}$. The lateral alkyl chain of these aromatics is oxydized to yield alkylbenzoates, which are further metabolized to Krebs cycle intermediates via benzoates and alkylbenzoates. The bacterium exhibits several blocks to the metabolism of $p$-ethylbenzoate (Fig. 2). Through the introduction of a series of mutations in the TOL plasmid, we constructed pWW0-EB62, a recombinant TOL plasmid that allows the host microbe to grow on $p$-ethylbenzoate while maintaining its ability to grow on benzoate and $m$ - and $p$-methylbenzoate ${ }^{18}$. The strategy involved the isolation of $x y l S 4$, a meta-cleavage pathway regulator mutant that recognizes $p$-ethylbenzoate as an effector ${ }^{12}$. The mutant regulator exhibited a single amino acid change with respect to the wild-type protein, arginine 45 being replaced by threonine. When the mutant regulator was introduced in Pseudomonas bearing the TOL plasmid, $p$-ethylbenzoate was oxydized to $p$-ethylcatechol, which inactivated catechol 2,3-dioxygenase (Fig. 2). We then isolated a mutant gene $x y / E 106$ encoding an enzyme resistant to inactivation by its substrate: $p$-ethylcatechol. The mutant catechol 2,3-dioxygenase exhibits a single amino acid substitution (threonine $253 \rightarrow$ isoleucine) (Wasserfallen, personal communication). The $x y l S 4$ and $x y l \mathrm{E} 106$ mutations were recombined in the TOL plasmid pWW0-EB62 so that the bacteria grew on 4ethylbenzoate as the sole $\mathrm{C}$-source (Fig. 2). This microbe has been extensively studied in microcosms (see below).

2. Pseudomonas sp. B13 exhibits two ortho-cleavage pathways, one each for the metabolism of benzoate and the other for catabolism of 3-chlorobenzoate ${ }^{19}$. These pathways do not allow the mineralization of other chlorobenzoates or alkylbenzoates ${ }^{13}$. The chromosomal ortho-cleavage pathway for benzoate seems to be similar to other catabolic pathways for the metabolism of benzoate by pseudomonadaceae. The 3-chlorobenzoate pathway is partially chromosome encoded and partially plasmid encoded. In this pathway, 3-chloroben- 
zoate is first oxydized to 3-chlorocatechol by chromosome encoded genes (Fig. 3); then 3-chlorocatechol undergoes ring cleavage and chlorine elimination, a process in which three plasmid-encoded enzymes-catechol 1,2-dioxygenase, chloromuconate cycloisomerase and dienelactone hydrolase -are involved. Growth of the bacteria on 3-chlorobenzoate resulted in amplification of the plasmid encoded genes involved in the process, in order to increase protein dosage ${ }^{20}$. Pseudomonas sp. B13 cannot grow on 4-chlorobenzoate or mixtures of alkyl- and halobenzoates. In contrast, Pseudomonas sp. FR1 (pFRC20P), a derivative of B13 that was constructed through the recruitment of genes from different microorganisms, is able to grow on 4-chlorobenzoate (Fig. 3) and mixtures of alkyl- and chloroaromatics ${ }^{14}$. Its construction involved chromosomal integration of the genes for the metabolism of 4-chlorobenzoate and alkylbenzoates to 4-chlorocatechol and alkylcatechols respectively. The construct was completed by the introduction of a mobilizable plasmid (pFRC20P) carrying a key gene for the conversion of alkyl-lactones resulting from the metabolism of alkylcatechols. The genes encoding the TOL plasmid toluate dioxygenase (xylXYZ) and the next enzyme in the pathway (a dehydrogenase encoded by $x y(L)$ ) plus the positive regulator $x y l \mathrm{~S}$, were cloned into $\mathrm{Tn} 5$ and delivered into the host chromosome. This allowed the recombinant bacteria to grow on 4-chlorobenzoate, and allowed the metabolism of 4-methylbenzoate to $\gamma$-methyl-lactone. The resulting bacterium was called Pseudomonas sp. FR1. Cloning of an isomerase from Alcaligenes that allowed the conversion of the $\gamma$-methyl-lactone into $\beta$-methyl-lactone ${ }^{21}$ in plasmid pFRC20P allowed mineralization of the alkylbenzoate. Further, this isolate grew, and simultaneously assimilated, mixtures of alkyl- and halobenzoates. Both Pseudomonas sp. B13 and FR1 (pFRC20P) have been studied in soil and aquatic microcosms.

The bioremediation of sites polluted by compounds at very low concentrations may be favored by microbes able to grow in plant rhizospheres, where the nutrient supplied by the plant may help to colonize soil sites poor in available substrates and ultimately improve the elimination of pollutants ${ }^{22}$. Pseudomonas fluorescens sp. F113, an isolate from the sugarbeet rhizosphere, is an excellent root colonizer and shows potential for serving as an instrument of biological control ${ }^{22}$. This microbe has been subjected to pathway expansion to include biphenyl' ${ }^{9}$. Improving the aerobic degradation of polychlorinated biphenyls is of current interest, although the aerobic process is limited to some congeners, which in most cases yield chlorobenzoates ${ }^{23}$. The $b p h$ gene cluster seems to be designed to deal with the unsubstituted substrate. Pseudomonas sp. F113-PCB is a derivative that carries the $b p h$ $\mathrm{A}_{1,2.3,4} \mathrm{BCD}$ genes for the conversion of biphenyl into benzoate. The bph genes were cloned into a mini-Tn 5 operon encoding resistance to biolaphos in the suicide plasmid pDDPCB $^{9}$, and then delivered into the host chromosome through this vector system.

Pseudomonas sp. clone A is a natural isolate that uses 2,4,6trinitrotoluene (TNT) as the sole $\mathrm{N}$-source. The microbe removes all three nitro groups successively from the nitroarene ring to yield toluene, which cannot be used as a Csource by this strain since it lacks the enzymatic machinery to oxydize this hydrocarbon. Because Pseudomonas sp. clone A belongs to rRNA group I, it was reasoned that the transfer of a $\mathrm{Km}^{r}$-TOL plasmid should allow this isolate to mineralize TNT. Matings between Pseudomonas sp. clone A and $P$. putida (pWW0-Km) yielded $\mathrm{Km}^{r}$ transconjugants of clone $\mathrm{A}$, which used TNT as the sole $\mathrm{C}$ - and $\mathrm{N}$-source ${ }^{8}$. This strain has been shown to eliminate TNT in waste waters

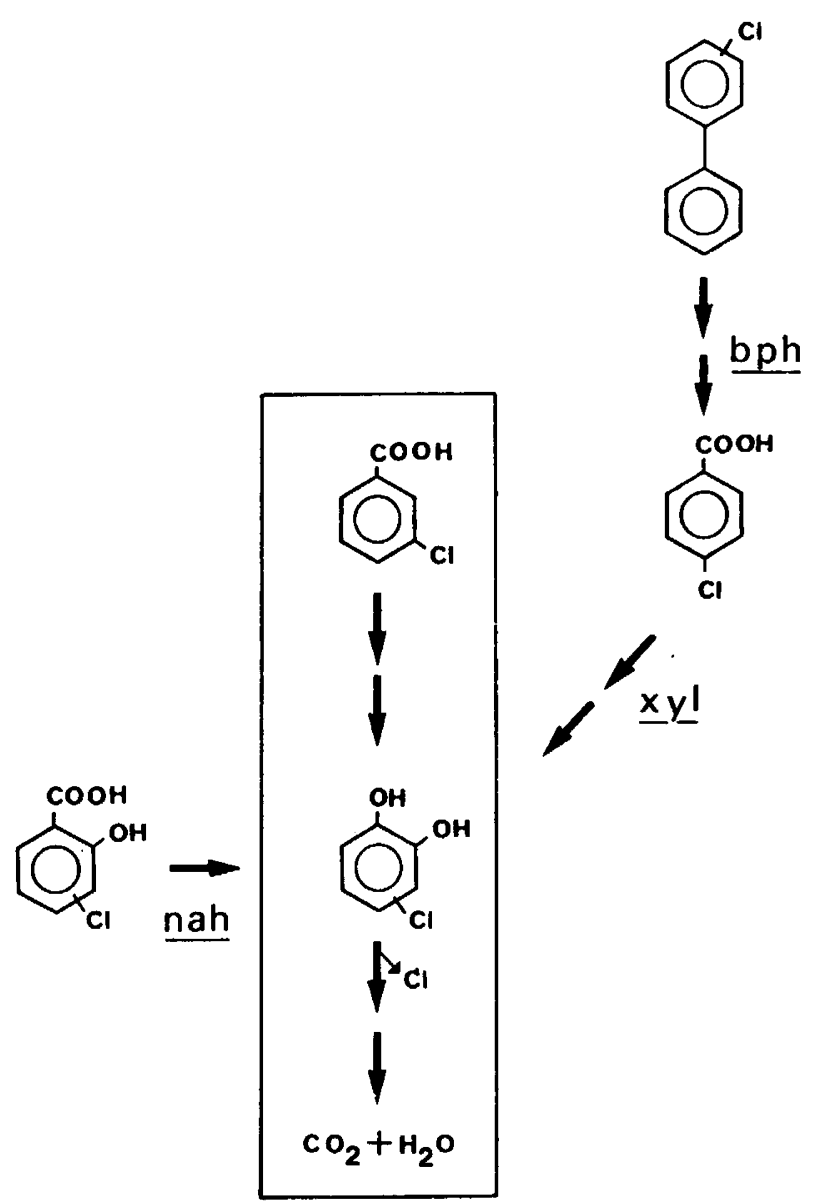

FIGURE 3. Schematic representation of some hybrid pathways for metabolism of aromatics. 3-chlorobenzoate is converted into 3-chlorocatechol by Pseudomonas sp. B13. The 3-chlorocatechol pathway sequent has been expanded to include chlorosalicylates 10 (nahG,R), 4-chlorobenzoate 13,14 (xyIXY$\mathrm{ZL}, \mathrm{S})$ and monochlorinated biphenyls $\left(\mathrm{bphA}_{1,2,3,4} \mathrm{BCD}\right)$.

from a factory manufacturing this compound (E. Duque, personal communication).

5. Mercury $(\mathrm{Hg})$ is a toxic metal that has been released into the environment in substantial quantities. Its toxicity results from the capacity of $\mathrm{Hg}$ (II) to bind sulfhydryl, thioether and imidazole groups and thereby inactivate enzymes ${ }^{24}$. Organic species of mercury, both alkyl and aromatic derivatives, accumulate in tissues of higher organisms generating serious health problems ${ }^{26}$. The merTPABD genes of transposon $\mathrm{Tn} 501$, which encodes the enzymes involved in organomercury resistance ${ }^{25}$, were cloned into a mini-Tn 5 that was used to insert the genes into the genome of $P$. putida. Transconjugants expressing constitutively the mer genes on basis to high resistance to phenylmercury were selected ${ }^{24}$. This allowed the engineered bacteria to cleave $\mathrm{Hg}$ from an organic moiety and reduce the liberated $\mathrm{Hg}(\mathrm{II})$ to $\mathrm{Hg}(0)$. These properties were also combined with benzene and toluene catabolism of several Pseudomonas strains, allowing the degradation of its aromatic moiety as well as detoxification of the metal component.

\section{Tracking GEMs in Microcosms}

Most of the recombinant bacteria constructed for biodegra- 
dation bear antibiotic resistance markers. Although these markers are extremely useful in molecular genetics and microbial ecology, their use in uncontained applications is perceived as less desirable ${ }^{27}$. To avoid their use in GEMs designed for environmental applications, a series of nonantibiotic resistance markers were developed. These include spontaneous resistance to the herbicide phosphinothricin ${ }^{28}$, cloned resistances to bialaphos, resistance to heavy metal ions such as mercury, arsenate or tellurite ${ }^{29,30}$ and nutritional markers such as the genes that enable the organism to grow on lactose as the sole Csource $^{31}$. Some of these markers were introduced into host microorganisms via mini-Tn5 derivatives ${ }^{6,29,30}$. Another approach, which may ultimately solve the problem of the persistance of selectable markers, is the use of a selectable marker, ie kanamycin resistance, flanked by two tandem res (resolution) sites of plasmid RP4, which can be provided as a cassette within a mini-transposon ${ }^{32}$. The res site is a short sequences which, once recognized by the resolvase of the ParA system, undergoes a site-specific recombination event that results in the deletion of the intervening DNA sequences ${ }^{33}$. ParA can be provided in a suicide replicon.

An alternative marker is the use of genes encoding light activities, such as $l u x$ and $l u c^{34}$. This system has now been used to mark and track Pseudomonas strains able to attach to maize plant roots (C. Ramos, unpublished).

An alternative to the introduction of a selectable marker in the target strain is to make use of means that specifically recognize the target microbe. Monoclonal antibodies (mAbs) are powerful tools for tracking microorganisms because they can recognize epitopes on the surface of bacteria, and thus serve as in situ identifiers. A series of mAbs were raised against whole cells of Pseudomonas putida KT244035. One was shown to recognize the O-antigen of Pseudomonas putida LPS. In the laboratory, this mAb specifically recognized the strain when grown in different culture media and at different growth stages. The mAb, which is highly specific, was used to track the strain after its release in a mesocosm established in the Plussee Lake in northern Germany ${ }^{35}$.

Another approach used in our laboratories has been to introduce new epitopes on a bacterial surface protein. For example, a mammalian coronavirus epitope ${ }^{36}$ has been cloned into the PAL protein, a surface protein of $P$. putida, and is now being used as a reporter to track bacteria bearing rDNA (J.J. Rodríguez-Herva and J.L. Ramos, unpublished).

Amplification of chromosomal genes from a highly specialized subpopulation of the total microbial community from the top layer sediment of the Elbe river made it possible to identify aerobic microbes able to degrade biphenyl ${ }^{37}$. The use of direct gene probes and PCR is a powerful approach to detect microorganisms without previous cultivation ${ }^{38}$.

\section{Features to be Analyzed with Recombinant Bacteria}

A series of features that are crucial for the safe and effective functioning of some of the above recombinant and wild-type bacteria have been examined in soil microcosms with and without plants, and in sewage microcosms:

(i) The ability of the bacterium to survive and multiply in the microcosms into which it is introduced;

(ii) the stability of the introduced genetic material;

(iii) effects, if any, of the GEMs on the structure and function of the microcosms into which it is introduced;

(iv) the ability of the recombinant microbe to effectively carry out the activity for which they were designed under the conditions prevailing in the microcosm;

(v) the potential of the new genetic material to transfer laterally to other microorganisms; (vi) coupling of a biological containment system to the catabolic pathways, so that programmed cell death can be designed;

(vii) design of barriers to gene dispersal.

\section{Survival and Propagation of GEMs in Their Target Ecosystem}

Microcosms offer a suitable approach to evaluate the survival and functioning of GEMs, however, it should not be ignored that the samples are taken from nature and introduced into the laboratory. This imposes some limitations, since a number of parameters are closely controlled, ie incubation temperature, humidity, light/dark cycles, etc. The survival of some of the recombinant microbes described above was assayed by introducing both parental and recombinant strains in soil, rhizosphere and aquatic microcosms. The microcosms used were: (i) sandyloam agricultural soils, whose $\mathrm{pH}$ were in the range of 7.0 to 7.5 and in which sugarbeet or maize seeds were introduced as required, and (ii) sewage water from a city water treatment plant. These recombinant bacteria had been designed to eliminate pollutants and they would be added to polluted soils and aquatic microcosms in relatively high numbers, eg, $10^{6}-10^{8}$ colony forming units (CFU) per gram of soil or milliliter of sewage water.

Most of the studies have focused on the behavior of these microbes during the initial period after introduction into the microcosms, usually between 4 and 8 weeks. It was generally observed that both the recombinant microbes and their parental strains were able to establish in soil, rhizosphere and aquatic microcosms. In each ecosystem the number of bacteria tended to reach the microcosm's carrying capacity, so that in microcosms rich in organic matter the number of microbes was usually higher than in microcosms poor in nutrients ${ }^{28,39,44}$.

Recombinant bacteria survived better than the parental strains only when they were introduced in soil or aquatic microcosms in which up to $0.1 \%$ (wt/wt or wt/vol) pollutant had been added, ie, conditions strongly favorable for the GEM. For instance, introduction of $P$. putida EEZ15 (pWW0-EB62) or $P$. putida sp. FR1 (pFRC20) in soils supplemented with $0.1 \%$ (wt/wt) $p$-ethylbenzoate and $p$-methylbenzoate, respectively, allowed the strain to become established at at least one order of magnitude higher than in soils without the supplement ${ }^{28,40}$. A similar observation was made when these bacteria were introduced in microcosms consisting of water from a sewage treatment plant ${ }^{42.43}$. Although survival of parental and recombinant bacteria approached $100 \%$ in short term experiments, in the long term a steady decline was observed in CFU per gram of soil, until numbers in some cases were below our detection limits $^{45}$

Both recombinant and parental bacteria not only survived in soils but also multiplied. In fact, following introduction of a low number, ie $10^{4} \mathrm{CFU}$ per gram of soil of $P$. putida (pWW0-EB62) in non-sterile soils it multiplied to reach a density of $10^{6}$ to $10^{7}$ CFU per gram of soil ${ }^{28}$.

The stability of the genetic information introduced in Pseudomonas sp. FR1 (pFRC20P), F113-PCB and $P$. putida EEZ15 (pWW0-EB62) has been studied ${ }^{28.39 .40}$. These strains are genetically stable bacteria since the phenotype acquired through the genetic manipulation was maintained under laboratory culture conditions in the absence of selective pressure. Furthermore, some natural properties of these strains, not related to the recombinant phenotype, ie biocontrol traits, growth rates, pigment production, etc, remained unaltered ${ }^{22}$. The recombinant trait did not affect the competence ability of the F113-PCB strain in colonization assays in non-sterile soil microcosms on sugarbeet seedling roots ${ }^{39}$. Furthermore, these strains have been shown to be stable in soil, since $100 \%$ of the recovered bacteria 
after prolonged incubation in soil retained the ability to use the aromatic compounds for which they were designed to deal. The effects of the introduction of wild-type or recombinant microbes on the indigenous microbiota have been studied either by estimating the "total" number of culturable microbes in relatively rich medium, ie, peptone agar, or by using the indigenous population able to use a compound as the sole $\mathrm{C}$-source, ie $p$ hydroxyphenylacetic acid degraders, the denitrifing bacteria or the "heterotrophic" population ${ }^{42,43}$ (M.C. Ronchel et al., unpublished). In general, it has been observed that neither the wildtype nor the recombinant microbe affected the parameter studied, which suggests that natural environments have a certain buffering capacity to deal with the introduced microbes.

The above cases suggest that the possible risk derived from the use of recombinant microbes in bioremediation are similar to those posed by the parental non-modified strains. It also seems that the physico-chemical and biological parameters of the microcosms affect equally the parental and recombinant microbes.

\section{Functionality of Recombinant Microbes in Target Microcosms}

The introduction of bacterial strains into the environment for in situ bioremediation will usually require that microorganisms be able to survive in high numbers and express the desired catabolic phenotype.

For pollutants to be efficiently mineralized by natural and genetically modified microbes, the degrading microbe not only must become established in the polluted sites, but also express catabolic genes in response to the pollutant, even in the presence of other compounds. Soils, river sediments and sewage treatment plants are complex environments in which gene expression can be inhibited or stimulated. Pseudomonas putida harboring either the wild-type pWW0 or the recombinant TOL plasmid were able to mineralize ${ }^{14} \mathrm{C}$-labeled substrates, eg, $p$-methyl $-{ }^{14} \mathrm{C}$ benzoate, for at least a month ${ }^{46}$. In soils, mineralization was monitored as evolution of ${ }^{14} \mathrm{CO}_{2}$, whereas in aquatic microcosms, metabolism of alkyl- and chloroaromatics was chromatographically monitored by measuring the disappearance of the target chemical from the polluted site $^{43}$. It was shown that Pseudomonas sp. FR1 (pFRC20P) enhanced the rate of degradation of a mixture of 3-chlorobenzoate and 4-methylbenzoate which had been added to the water column of sediment ores made of intact layered sediments from the Plussee Lake and the Rhine River ${ }^{43}$. Pseudomonas sp. FR1 bearing the $b p h$ genes inserted on the chromosome was able to remove up to $100 \mathrm{ppm}$ of 4-chlorobiphenyl per $\mathrm{g}$ of sediment slurry in 5 days'. In these assays, recombinant bacteria were established at close to $10^{8}$ CFU per g of sediment.

\section{Transfer of Recombinant DNA from \\ Pseudomonas to Other Microorganisms}

Gene transfer from recombinant microbes has been analyzed under optimal laboratory conditions and in soil and aquatic microcosms. The genetic information introduced into Pseudomonas F113-PCB was inserted into the host chromosome via a mini-Tn5 lacking the transposase gene. In the case of Pseudomonas sp. FR1 (pFRC20P) the information was partially located on the bacterial chromosome ( $\mathrm{Tn} 5: x y l \mathrm{XYZ}, x y l \mathrm{~S})$ and partially on a mobilizable broad-host-range plasmid (pFRC20P). In $P$. putida (pWW0-EB62) the recombinant information was on a self-transmissible TOL plasmid. The recombinant DNA in these three strains was stably maintained under laboratory growth conditions, as well as in bacteria introduced into soil and aquatic microcosms. In the laboratory there was no transfer of the recombinant DNA from the chromosome of Pseudomonas sp. F113-PCB or Pseudomonas sp. FR1 (pFRC20P) to other
A

SURVIVAI
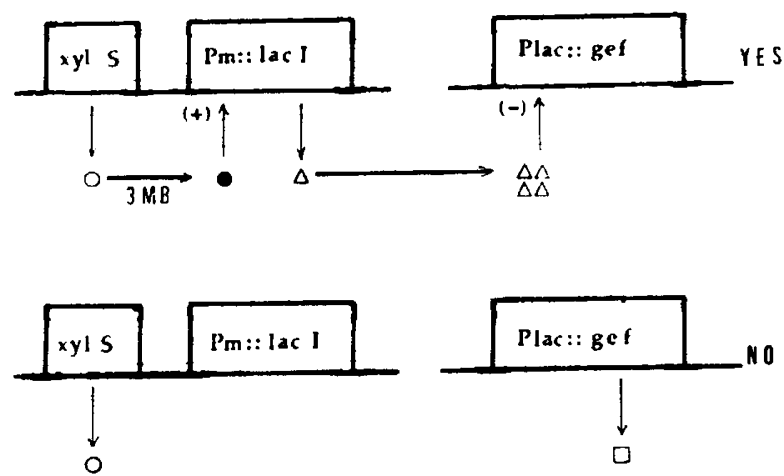

B

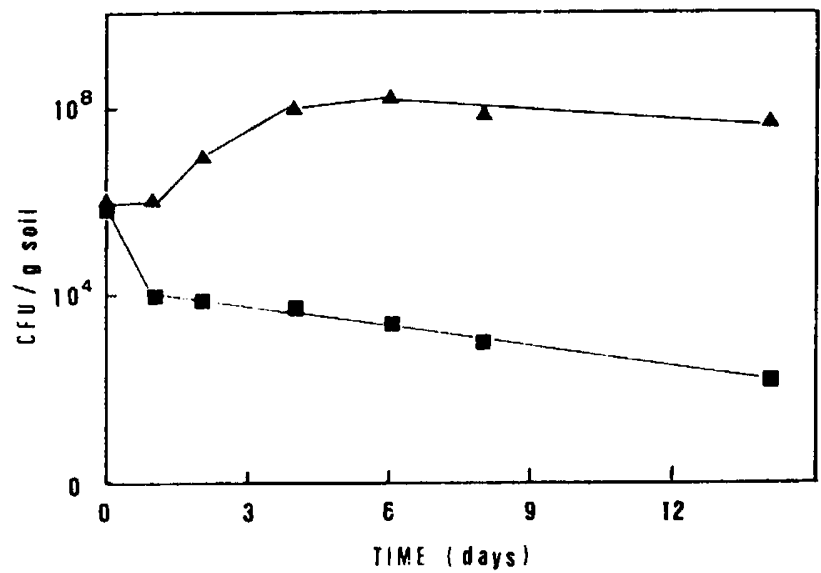

FIGURE 4. Programmed survival and death of Pseudomonas putida bearing a conditional containment system based on the presence or absence of a pollutant. (A) The biological containment system is an example of those designed to control survival of bacteria by modifying the availability of nutrientes in this case, $m$-methylbenzoate (3MB). (B) Behavior in soil of a contained bacteria in the presence $(\Delta)$ and in the absence of m-methylbenzoate ( $\square$ ).

Pseudomonas, or to indigeneous bacteria in soil and aquatic microcosms ${ }^{39,40,42}$. In contrast, plasmid pFRC20P was transferred to other microbes, but only if a helper plasmid was supplied in the mating mixture ${ }^{40}$. In these cases, transfer of the plasmid led to about $10^{-5}$ transconjugants per recipient. Transfer of the wild-type TOL plasmid or the recombinant pWW0-EB62 was restricted to microorganisms belonging to members of the pseudomonad rRNA group I ( $P$. putida, $P$. fluorescens, $P$. stutzeri, etc.) and some enterobacteriaceae. In matings on plates the rate of TOL transfer was of the order of 1 to $10^{-2}$ transconjugants per recipient, and the rate of intergeneric transfer ranged from $10^{-4}$ to $10^{-8}$ transconjugants per recipient $t^{47}$.

In soils, the TOL plasmid was transferred from $P$. putida to other strains of Pseudomonas only at high cell densities (higher than $10^{\circ} \mathrm{CFU} / \mathrm{g}$ soil). Transfer was influenced by the type of soil used, the incubation temperature, the initial inoculum size and the presence of chemicals that affected the survival of donor or recipient bacteria. Maximal transfer was observed in soils incubated at 15 to $17^{\circ} \mathrm{C}$, when the donor and recipient loads were about $10^{8} \mathrm{CFU}$ per $\mathrm{g}$ of soil $^{47}$.

In conclusion, recombinant DNA can be transferred between microorganisms. Transfer is limited by the vector used to introduce the recombinant DNA into the host microbe and by the 
FIGURE 5. Gene containment system based on a lethal donation of a killing function. Barriers to gene transfer were designed to avoid the establishment of rDNA in hosts other than those specifically designed as recipients.
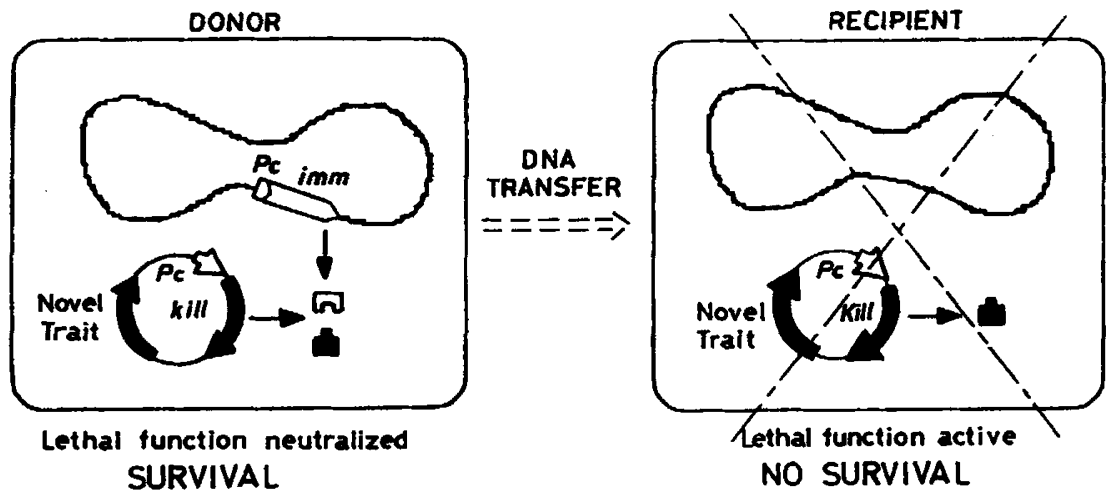

nature of the recipient microorganism. Chromosomal information is less likely to be transferred than is information on mobilizable plasmids. The latter is less likely to be transferred than recombinant DNA on self-transmissible plasmids.

Not all locations on the chromosome are similar in terms of expression, physical structure or mobilization. This is particularly true in Pseudomonas where most auxotrophic markers are located on only $50 \%$ of the chromosome ${ }^{48}$. Ramos-González et al. ${ }^{49}$ labeled the chromosome of $P$. putida randomly at 34 independent positions with the same marker, a mini-Tn5-Km. It was shown that the TOL plasmid was able to mobilize these insertions on the host chromosome at a rate between $10^{-4}$ and $10^{-8}$ transconjugants/recipient. Furthermore, the mobilization of the host chromosome by TOL occurred when the TOL plasmid and the marked chromosome were located in the two independent microbes, a phenomenon called retrotransfer. Retrotransfer involves the movement of a self-transmissable replicon to a recipient organism, the capture of DNA, and its return to the original donor $^{50}$. It then follows that, although chromosomal insertions are less likely to be mobilized than rDNA on plasmids, they can nonetheless potentially undergo transfer.

\section{Biological Containment Based on Substrate Availability}

The full exploitation of recombinant microbes for bioremediation will inevitably involve their release in the environment, where non-controlable conditions prevail. This issue raises a series of scientific and public concerns due to the lack of knowledge on the behavior and fate of microbes in the environment. This also raises an inevitable question, can we extrapolate the results obtained in microcosms to the "real" scenario, the open environment?

The goal behind "biological containment" is that of increased predictability in the behavior and fate of recombinant microbes ${ }^{51}$. Biological containment can be passive, ie through the impairment of strains by the introduction of mutations (auxotrophies, recA-, etc.), or active, this is based on genes that induce cell killing ${ }^{51}$. The active system imposes a series of criteria, namely, (i) the killing efficiency should be high, (ii) the killing gene should perform effectively in a wide range of microbes, (iii) the suicide system should not interfere with the "modifications" introduced in the microbes and (iv) the mutation rate of the killing system should be as low as possible ${ }^{52}$.

One model case of chemical induction of suicide as a biological containment principle (for release purposes) was developed for the biodegradation of xenobiotics. The strategy was to combine the killing function with the regulatory system of a degradative pathway in such a way, that the cells survive in the presence of the xenobiotic (repression of the killing gene), but after completion of degradation of the compound the killing gene is turned on, and the cells die ${ }^{53}$. This approach has been tested in relation to the TOL pathway responsible for the mineralization of different benzoates. With the detailed knowledge about the genetic control of the genes involved in this degradative pathway $^{54}$, it was possible to design engineered combinations of the expression system of the TOL genes and a suicide gene. One of the promoters of the TOL genes was fused with the $E$. coli lacI gene whose product represses a promoter, $P_{\text {lac }}$ which in the present context was fused with the killing gene (Fig. 4). In the presence of $m$-methylbenzoate the TOL promoter is activated, which implies that the repressor protein is made, and consequently the killing function is not expressed; the cells survive, and degradation of $m$-methylbenzoate is allowed. After removal of the aromatic inducer the repressor is no longer expressed from the TOL promoter, and therefore no inhibition is exerted on the promoter responsible for expression of the killing function $^{55}$. After completion of the task of the designed organism (degradation of $m$-methylbenzoate), it destroys itself through substrate regulated induction of the suicide system.

It should be emphasized that effective containment systems can only be constructed if the performance of the organism in the proper environmental context is at least partially characterized. In fact, this biological containment system was shown to function in soils ${ }^{55}$ (Fig. 4).

\section{Universal Barriers to Gene Dispersal}

To address concerns due to the potential transfer and spread of rDNA into the native population of microorganisms, a genetic circuit to suppress lateral spread of cloned genes from recombinant microbes to indigenous microorganisms was conceived ${ }^{56}$ (Fig. 5). The system involves two genes, the colE3 gene, encoding the RNAse colicin E3, and the immunity immE3 gene, which codes for a specific inhibitor of the lethal function, the immunity E3 protein ${ }^{57}$. The target of colicin E3 is located at the $3^{\prime}$ end of the 16S rRNA which is conserved virtually in all prokaryotic and some eukaryotic genera ${ }^{58}$. Cleavage of this sequence separates the mRNA binding sites from the remainder of the 16S rRNA, thereby inhibiting protein synthesis and leading to cell death. In the GEM, the gene specifying the lethal function is closely linked to the determinant of the novel phenotype, whereas the immunity gene is located far from the recombinant genes, so that co-transfer of immunity gene with the kill gene is highly unlikely. Transfer of the determinant of the novel phenotype to a new organism will be accompanied by transfer of the lethal function, but not of the immunity function, and as a consequence the recipient organism will be killed (Fig. 5). The genes colE3 and immE3 have been cloned and constitutively expressed separately ${ }^{56}$. The $i m m E 3$ gene was integrated into the 
chromosome of different $E$. coli and Pseudomonas putida strains. On the other hand, the colE3 gene was cloned in a promiscuous plasmid able to replicate both in gram-positive and gram-negative bacteria. Effectiveness of the containment system was tested with different DNA transfer mechanisms (transformation and conjugation), and different recipient microorganisms of environmental importance. There were representative of the main subgroups of Proteobacteria: $P$. putida and $P$. fluorescens ( $\gamma$ subgroup), Alcaligenes eutrophus and Comomonas acidovorans ( $\beta$ subgroup), Rhizobium meliloti and Agrobacterium tumefaciens ( $\alpha$ subgroup). In all cases the colicin E3 lethal function decreased the frequency of plasmid transfer by four to five orders of magnitude. In combination with transposon cloning vectors, the circuit is predicted to reduce the lateral spread of specific genes to extremely low levels and to increase substantially the ecological predictability of novel recombinant microorganisms.

\section{Future Prospects}

To bring about in vitro evolution of the catabolic pathways usually requires a through knowledge on the biochemistry of the reactions involved in the degradation of a compound and of the genetics of the pathway, ie the organization of the genes encoding for the enzymes and the operation of the regulatory circuits governing the activation of gene expression. In recent years a number of new catabolic pathways dealing with toxic and recalcitrant compounds have been elucidated. These include pathways for the metabolism of dibenzodioxins, new pathways for chloroaromatics, polar and apolar nitroaromatics such as nitrobenzoates and mono- and poly- substituted nitrotoluenes ${ }^{8.59-62}$. Equally important is that many enzymes are extremely relaxed in their substrate specificity, which makes them able to deal with multiple substrates. In fact, some dioxygenases are able to function as monoxygenases ${ }^{62}$, and some dioxygenases for the metabolism of aromatics attack compounds with two and three aromatic rings, as well as heterocycles. It is therefore expected that new catabolic pathways will be constructed based on these catabolic modules, and therefore, the number of microbes mineralizing halo- and nitrosubstituted aliphatic and aromatics, organic solvents, plaguicides and other xenobiotics should increase steadily.

Bioremediation research done in simulated environments does not accurately represent truly environmental conditions and, therefore, such experiments cannot test how prospective bioremediation schemes respond to changes in the weather and movement of materials that may typify polluted sites. For these reasons, and to more fully address concerns regarding the safety and reliability of approaches now being developed, carefully controlled field studies for bioremediation seems to be the logical next step. The deliberate release of GEMs in the environment raises a series of scientific and public concerns, and biological containment can provide a means to increase the predictability in the behavior and fate of recombinant microbes $^{51}$.

\section{Acknowledgments}

The work carried out in the authors laboratories was mainly supported by a BRIDGE grant from the European Commission (BIO-CT-92-0284).

\section{References}

1. Keith, L. H. and Telliard, W. A. 1979. Prioritary pollutants I-a perspective view. Environm. Sci. Technol. 13:416-423.

2. Ramos, J. L. and Timmis, K. N. 1987. Experimental evolution of catabolic pathways of bacteria. Microbiol. Sci. 4:228-237.

3. Pemperton, J. M. and Fisher, P. R. 1977. 2,4-D plasmids and persistence. Nature 268:732-733

4. Slater, J. H. and Bull, A. T. 1982. Environmental microbiology: biodegradation. Phil. Trans. R. Soc. Lond. B 297:575-597.

5. Subba-Rao, R. V. and Alexander, M. 1985. Bacterial and fungal cometabolism of 1,1,1-trichloro-2,2-bis (4-chlorophenyl) ethane (DDT) and its breakdown products. Appl. and Environm. Microbiol. 49:509-516.

6. De Lorenzo, V., and Timmis K.N. 1994. Analysis and construction of stable phenotypes in gram-negative bacteria with $\mathrm{Tn} 5$ and $\mathrm{Tn} 10$-derived mini-transposons. Methods Enzymol. 235:386-405.

7. Abril, M. A., Michán C., Timmis, K. N. and Ramos, J. L. 1989. Regulator and enzyme specificities of the TOL plasmid-encoded upper pathway for degradation of aromatic hydrocarbons and expansion of the substrate range of the pathway. J. Bacteriol. 171:6782-6790.

8. Duque, E., Haidour, A., Godoy, F. and Ramos, J. L. 1993. Construction of a Pseudomonas hybrid strain that mineralizes 2,4,6-trinitrotoluene. J. Bacteriol. 175:2278-2283.

9. Dowling, D. N., Pipke, R. and Dwyer, D. F. 1993. A DNA module encoding $b p h$ genes for the degradation of polychlorinated biphenyls (PCBs). FEMS Microbiol. Lett. 113: 149-154.

10. Lehrbach, P. R., Zeyer, J., Reineke, W., Knackmuss, H.-J. and Timmis, K. N. 1984. Enzyme recruitment in vitro: use of cloned genes to extend the range of haloaromatics degraded by Pseudomonas sp. strain B13. J. Bacteriol. 158: $1025-1032$.

11. Ramos, J. L., Stolz, A., Reineke, W. and Timmis, K. N. 1986. Altered effector specificities in regulators of gene expression: TOL plasmid $x y l S$ mutants and their use to engineer expansion of the range of aromatics degraded by bacteria. Proc. Natl. Acad. Sci. USA 83:8467-8471.

12. Ramos, J. L., Wasserfallen, A., Rose, K. and Timmis, K. N. 1987. Redesigning metabolic routes: manipulation of TOL plasmid pathway for catabolism of alkylbenzoates. Science 235:593-596.

13. Reineke, W. and Knackmuss, H.-J. 1979. Construction of haloaromatic-utilizing bacteria. Nature 277:385-386.

14. Rojo, F., Pieper, D., Engesser, K. H., Knackmuss, H.-J. and Timmis, K. N. 1987. Assemblage of ortho cleavage routes for degradation of chloro- and methylaromatics. Science 238:1395-1398.

15. Sokacht, J. (Ed.). 1986. The Bacteria, vol X. The Biology of Pseudomonas. Academic Press, N.Y.

16. Galli, E., Silver, S. and Withold, B. (Eds.). 1992. In: Pseudomonas: Molecular Biology and Biotechnology. American Society for Microbiology. Washington DC

17. Mermod, N., Lehrbach, P. R., Don, R. H. and Timmis, K. N. 1986. Gene cloning and manipulation in Pseudomonas. p. 325-355. In: The Bacteria, vol. X, Sokatch, J. R. (Ed.). Academic Press, N.Y.

18. Worsey, M. J. and Williams, P. A. 1974. Metabolism of toluene and xylenes by Pseudomonas putida (arvilla) mt-2: evidence for a new function of the TOL plasmid. J. Bacteriol. 124:7-13.

19. Dorn, E., Hellwig, M., Reineke, W. and Knackmuss, H.-J. 1974. Isolation and characterization of a 3-chlorobenzoate degrading pseudomonad. Arch. Microbiol. 99:61-70.

20. Rangnekar, V. M. 1988. Variation in the ability of Pseudomonas sp. strain B13 cultures to utilize m-chlorobenzoate is associated with tanden amplification and deamplification of DNA. J. Bacteriol. 170:1907-1912.

21. Pieper, D. H., Engesser, K. H., Don, R. H., Timmis, K. N. and Knackmuss, H.-J. 1985. Modified ortho-cleavage pathway in Alcaligenes eutrophus JMP134 for the degradation of 4-methylcatechol. FEMS Microbiol. Lett. 29:63-67.

22. Dowling, D. N. and O'Gara, F. 1994. Genetic manipulation of ecologically adapted Pseudomonas strains for PCB degradation. In: Current Topics in Molecular Genetics. (Life Sci. Adv.) 2:1-8.

23. Bopp, L. H. 1986. Degradation of highly chlorinated PCBs by Pseudomonas strain LB400. J. Ind. Microbiol. 1:23-29.

24. Niebor, E. and Richardson, D. H. S. 1980. The replacement of the nondescript term "heavy metals" by a biologically and chemically significant classification of metal ions. Environm. Pollut. Ser. B. 1:3-26.

25. Lund, P. A. and Brown, N. L. 1989. Regulation of transcription in Escherichia coli from the mer and merR promoter in the transposon Tn501. J. Mol. Biol. 205:343-353.

26. Horn, J. M., Brunke, M., Deckwer, W.-D. and Timmis, K. N. 1994. Pseudomonas putida strains which constitutively overexpress mercury resistance for biodetoxification of organomercurial pollutants. Appl. Environm. Microbiol. 60:357-362.

27. Tiedje, J. M., Colwell, R. K., Grossman, Y., Hodson, R. E., Lenski, R. E., Mack, R. N. and Regal, P. J. 1989. The planned introduction of genetically engineered organisms: ecological considerations and recommendations. Ecology 70:298-315.

28. Ramos, J. L., Duque, E. and Ramos-González M.I. 1991. Survival in soils of an herbicide-resistant $P$ seudomonas putida strain bearing a recombinant TOL plasmid. Appl. Environm. Microbiol. 57:260-266.

29. Herrero, M., de Lorenzo, V. and Timmis, K. N. 1990. Transposon vectors containing non-antibiotic resistance selection markers for the cloning and stable chromosomal insertion of foreign genes in gram negative bacteria. J. Bacteriol. 172:6557-6567.

30. De Lorenzo, V., Herrero, M., Jacubzik, U. and Timmis, K. N. 1990. Mini-Tn5 transposon derivatives for insertion mutagenesis, promoter probing and chromosomal insertion of cloned DNA in gram-negative eubacteria. J. Bacteriol. 172:6568-6572.

31. Drahos, D. J., Barry, G. F., Hemming, B. C., Brandt, E. J., Skipper, H. D., Kline, E. L., Kluepfel, D. A., Hughes, T. A. and Gooden, D. T. 1988. Prerelease testing procedures: U.S. field test of a lacZY-engineered soil bacterium, p. 181-191. In: The release of genetically-engineered microorganisms, Sussman, M., Colling, C. H., Skinner, F. A. and Stewart-Tull, D. E. (Eds.). Academic Press, London.

32. Kristensen, C. S., Eberl, L., Sánchez-Romero, J. M., Givskov M., Molin, S. and de Lorenzo, V. 1994. Site-specific deletions of chromosomally located DNA segments with the multimer resolution system of broad-host-range plasmid RP4. J. Bacteriol. In press.

33. Eberl, L., Kristensen, C. S., Givskov, M., Grohmann, E., Gerlitz, M. and Schwab, H. 1994. Analysis of the multimer resolution system encoded by the parCBA operon the broad-host-range plasmid RP4. Mol. Microbiol. 12: 131-141. 
34. Prosser, J. J. 1994. Molecular marker systems for detection of genetically engineered micro-organisms in the environment. Microbiology 140:5-17.

35. Ramos-González, M. I., Ruíz-Cabello, F., Brettar, I., Garrido, F. and Ramos, J. L. 1992. Tracking genetically engineered bacteria: monoclonal antibodies against surface determinants of the soil bacterium Pseudomonas putida 2440. J. Bacteriol. 174:2978-2985.

36. Gebauer, F., Posthumus, W. P. A., Correa, I., Suñé, C., Smerdou, C., Sánchez, C. M., Lenstra, J. A., Meloen, R. H. and Enjuanes, L. 1991. Residues involved in the antigenic sites of transmissible gastroenteritis coronavirus $\mathrm{S}$ glycoptotern. Virol. 183:225-238.

37. Erb, R. W. and Wagner-Döbler, I. 1993. Detection of polychlorinated biphenyl degradation genes in polluted sediments by direct DNA extraction and polymerase chain reaction. Appl. Environm. Microbiol. 59:4065-4073.

38. Atlas, R. M. 1992. Molecular methods for environmental monitoring and containment of genetically engineered microorganisms. Biodegradation 3: 137-146.

39. Brazil, G. M., Kenefick, L., Callanan, M., Haro, A., de Lorenzo, V., O'Gara, F. and Dowling, D. N. 1994. Expanding the metabolic functions of a rhizosphere competent pseudomonad to degrade biphenyl: characterisation of Pseudomonas fluorescens F113pcb in non sterile soil microcosms. Submitted.

40. Delgado, A., Duque, E. and Ramos, J. L. 1992. Behavior in agricultural soils of a recombinant Pseudomonas bacterium that simultaneously degrades alkyl- and haloaromatics. Microb. Releases 1:23-28.

41. McClure, N. C., Weightman, A. J. and Fry, J. C. 1989. Survival of Pseudomonas putida UWC1 containing cloned catabolic genes in a model activatedsludge unit. Appl. Environm. Microbiol. 55:2627-2634.

42. Nusslein, K., Maris, D., Timmis, K. N. and Dwyer, D. F. 1992. Expression and transfer of engineered catabolic pathways harbored by Pseudomonas spp. introduced into activated sludge microcosms. Appl. Environm. Microbiol. 58:3380-3386.

43. Pipke, R., Wagner-Döbler, I., Timmis, K. N. and Dwyer, D. F. 1992. Survival and function of a genetically engineered Pseudomonad in aquatic sediment microcosms. Appl. Environm. Microbiol. 58:1259-1265.

44. Wagner-Döbler, I., Pipke, R., Timmis, K. N. and Dwyer, D. F. 1992 . Evaluation of aquatic sediment microcosms and their use in assessing possible effects of introduced microorganisms on ecosystem parameters. Appl. Environm. Microbiol. 58:1249-1258.

45. Duque, E., Ramos-González, M. I., Delgado, A., Contreras, A., Molin, S. and Ramos, J. L. 1992. Genetically engineered Pseudomonas strains for mineralization of aromatics: survival, performance, gene transfer, and biological containment, p. 429-437. In: Pseudomonas. Molecular Biology and Biotechnology. Gally, E., Silver, S., Withold, B. (Eds.). American Society for Microbiolgy. Washington DC

46. Duque, E., Marqués, S. and Ramos, J. L. 1993. Mineralization of p-methyl${ }^{14} \mathrm{C}$-benzoate in soils by Pseudomonas putida (pWW0). Microb. Releases 2:175-177.
47. Ramos-González, M. I., Duque, E. and Ramos, J. L. 1991. Conjugational transfer of recombinant DNA in cultures and in soils: host range of Pseudomonas putida TOL plasmids. Appl. Environm. Microbiol. 57:3020-3027.

48. Holloway, B. N. 1986. Chromosome mobilization and genomic organization in Pseudomonas, p. 217-250. In: The Bacteria, vol. X, J. Sokatch (Ed.). Academic Press, N.Y.

49. Ramos-González, M. I., Ramos-Díaz, M. A. and Ramos, J. L. 1994. Chromosomal gene capture mediated by the Pseudomonas putida TOL catabolic plasmid. J. Bacteriol. 176:4635-4641.

50. Mergeay, M., Lejeune P., Sadouk, A., Gerits, A. J. and Fabry, L. 1987. Shuttle transfer (or retrotransfer) of chromosomal markers mediated by plasmid pULB113. Mol. Gen. Genet. 209:61-70.

51. Molin, S., Boe, L., Jensen, L. B., Kristensen, C. S., Givskov, M., Ramos, J. L. and Bej, A. K. 1993. Suicidal genetic elements and their use in biological containment of bacteria. Ann. Rev. Microbiol. 47:139-166.

52. Molin, S. 1992. Designing microbes for release into the environment. Sci. Progress Oxford 76:139-148.

53. Contreras, A., Molin, S. and Ramos, J. L. 1991. Conditional-suicide containment system for bacteria which mineralize aromatics. Appl. Environm. Microbiol. 57:1504-1508.

54. Marqués, S. and Ramos, J. L. 1993. Transcriptional control of the Pseudomonas putida TOL plasmid catabolic pathways. Mol. Microbiol. 9:923-929.

55. Jensen, L. B., Ramos, J. L., Kaneva, Z. and Molin, S. 1993. A substratedependent biological containment system for Pseudomonas putida based on the Escherichia coli gef gene. Appl. Environm. Microbiol. 59:3713-3717.

56. Díaz, E., Munthali M., de Lorenzo, V. and Timmis, K. N. 1994. Universal barriers to lateral spread of specific genes among microorganisms. Mol. Microbiol. 13:855-861.

57. Jakes, K. S. 1982. The mechanism of action of colicin E2, colicin E3 and cloacin DF13, p. 131-167. In: Molecular Action of Toxin and Viruses. Cohen, P. and van Heyningen, S. (Eds.). Elsevier, Amsterdam. Biomedical Press.

58. Lasater, L. S., Cann, P. A and Glitz, D. G. 1989. Localization of the site of cleavage of ribosomal RNA by colicin E3. J. Biol. Chem. 264:21798-21805.

59. Blasco, R., Wittich, R.-M, Timmis, K. N. and Pieper, D. H. 1994. From xenobiotic to antibiotic: Ecotoxicity of some chloroaromatic pollutants is due to microbial formation of protoanemonin. Submitted.

60. Groenewegen, P. E. J., Breeuwer, P., van Helvoort, J. M. L. M., Langenhoff, A. A. M., de Vries, F. P. and de Bont, J. A. M. 1992. Novel degradative pathway of 4-nitrobenzoate in Comamonas acidovorans NBA-10. J. Gen. Microbiol. 138: $1599-1605$.

61. Spanggord, R. J., Spain, J. C., Nishino, S. F. and Mortelmans, K. E. 1991 Biodegradation of 2,4-dinitrotoluene by a Pseudomonas sp. Appl. Environm. Microbiol. 57:3200-3205.

62. Robertson, J. B., Spain, J. C., Haddock, J. D. and Gibson, D. J. 1992. Oxidation of nitrotoluenes by toluene dioxygenase: evidence for a monooxygenase reac tion. Appl. Environm. Microbiol. 58:2643-2648.

\section{If you can't picture assays in 5 minutes, we'd like to show you some slides.}

Insert.

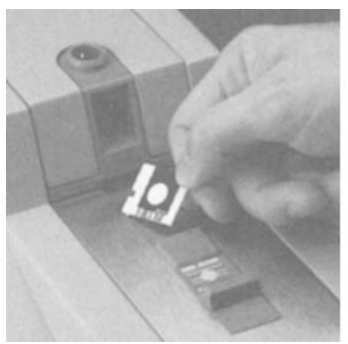

Sample.

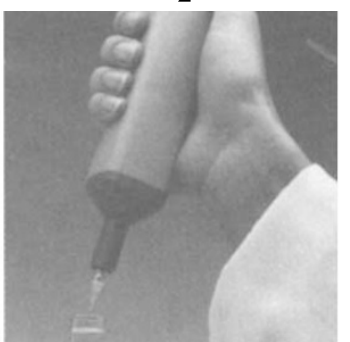

Pipette.

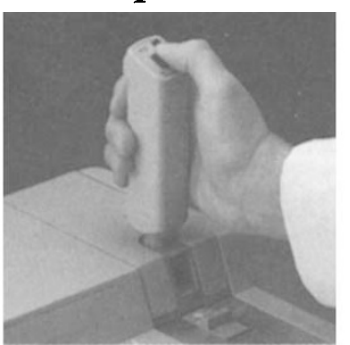

Read.

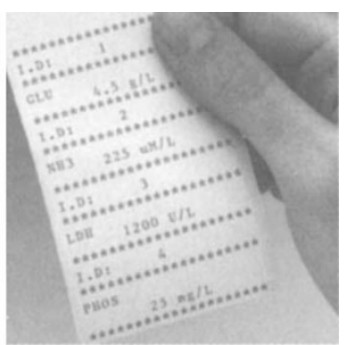

Patented Biolyzer" dry slides, to be precise.

You'll find them measuring glucose, ammonia, LDH phosphorus, lactate and other key analytes in major pharmaceutical and biotech labs across the U.S. The Biolyzer Rapid Analysis System is preferred for RED, process development and scale-up for its speed, convenience and reliability. You simply pipette directly from your sample onto the slide, push the button and watch your results print out. No wet chemicals. No sample prep. Try it in your facility. See how quickly and easily Biolyzer takes the headache out of process analysis. Call today for your free demonstration. One try and you'll agree, everything else is all wet. 1-800-243-2555. (203-786-5600). Or Fax: 203-624-3143 In the UK call: 0223242813 or Fax: 0223243036.

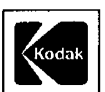

Scientific Imaging Systems

Applied Imaging

Eastman Kodak Company

P.O. Box 9558, New Haven, CT 06535 